\title{
Production of viable piglets for the first time using sperm derived from ectopic testicular xenografts
}

\author{
Michiko Nakai ${ }^{1}$, Hiroyuki Kaneko ${ }^{1}$, Tamas Somfai ${ }^{1}$, Naoki Maedomari ${ }^{1,2}$, Manabu Ozawa ${ }^{1}$, \\ Junko Noguchi ${ }^{1}$, Junya Ito $^{2}$, Naomi Kashiwazaki ${ }^{2}$ and Kazuhiro Kikuchi ${ }^{1}$ \\ ${ }^{1}$ Division of Animal Sciences, National Institute of Agrobiological Sciences, Tsukuba, Ibaraki 305-8602, Japan \\ and $^{2}$ Laboratory of Animal Reproduction, School of Veterinary Medicine, Azabu University, Sagamihara, Kanagawa \\ 229-8501, Japan \\ Correspondence should be addressed to K Kikuchi; Email: kiku@affrc.go.jp
}

M Nakai, H Kaneko and K Kikuchi contributed equally to this work

\begin{abstract}
Xenografting of testicular tissue into immunodeficient mice is known to be a valuable tool for facilitating the development of immature germ cells present in mammalian gonads. Spermatogenesis in xenografts and/or in vitro embryonic development to the blastocyst stage after ICSI of xenogeneic sperm has already been reported in large animals, including pigs; however, development of the embryos to term has not yet been confirmed. Therefore, in pigs, we evaluated the in vivo developmental ability of oocytes injected after ICSI of xenogeneic sperm. Testicular tissues prepared from neonatal piglets, which contain seminiferous cords consisting of only gonocytes/spermatogonia, were transplanted under the back skin of castrated nude mice. Between 133 and 280 days after xenografting, morphologically normal sperm were recovered, and a single spermatozoon was then injected into an in vitro matured porcine oocyte. After ICSI, the oocytes were electrostimulated and transferred into estrus-synchronized recipients. Two out of 23 recipient gilts gave birth to six piglets. Here, we describe for the first time that oocytes fertilized with a sperm from ectopic xenografts have the ability to develop to viable offspring in large mammals.

Reproduction (2010) 139 331-335
\end{abstract}

\section{Introduction}

Grafting of testicular tissue into immunodeficient mice enables the utilization of rare male genetic resources. In fact, sperm have already been obtained following entopic allografting (mouse; Shinohara et al. 2002), entopic xenografting (rabbit; Shinohara et al. 2002), ectopic allografting (mouse; Honaramooz et al. 2002, Schlatt et al. 2003), and ectopic xenografting (hamster; Schlatt et al. 2002; goat; Honaramooz et al. 2002; rhesus macaque; Honaramooz et al. 2002; sheep; Zeng et al. 2006; cat; Snedaker et al. 2004; and pig; Honaramooz et al. 2002, Zeng et al. 2006, 2007, Kaneko et al. 2008, Nakai et al. 2009) of testicular tissue. It has also been reported that xenogeneic sperm are fully functional for fertilization after ICSI (pig and goat; Honaramooz et al. 2002), and also for embryonic development to the blastocyst stage after ICSI (monkey; Honaramooz et al. 2004, pig; Honaramooz et al. 2008, Nakai et al. 2009). Until now, production of viable offspring has been limited to experimental animals using sperm from allografted (mouse; Schlatt et al. 2003) and xenografted (rabbit; Shinohara et al. 2002) testicular tissues. In large animals, however, successful production of viable offspring using sperm obtained from testicular tissue xenografted into immunodeficient mice has not yet been reported. In order for testicular grafting to become established as a powerful option for conserving mammalian male genetic resources, it is essential to ensure that the sperm isolated from such ectopic xenografts can also support full-term fetal development in large animals, including pigs.

\section{Results and Discussion}

Testicular grafts between 133 and 280 days after xenografting were used for obtaining sperm. Some of the tissues were subjected to histological examination, and this revealed seminiferous tubules both with and without completed spermatogenesis (Fig. 1A-C). This result is in agreement with our previous study, which indicated that spermatogenesis was complete in testicular grafts at least 120 days after xenografting (Kaneko et al. 2008). Morphologically normal sperm, which consisted of a head with an intact acrosome, midpiece, and tail, were isolated from the testicular grafts $(89.3 \%$ 


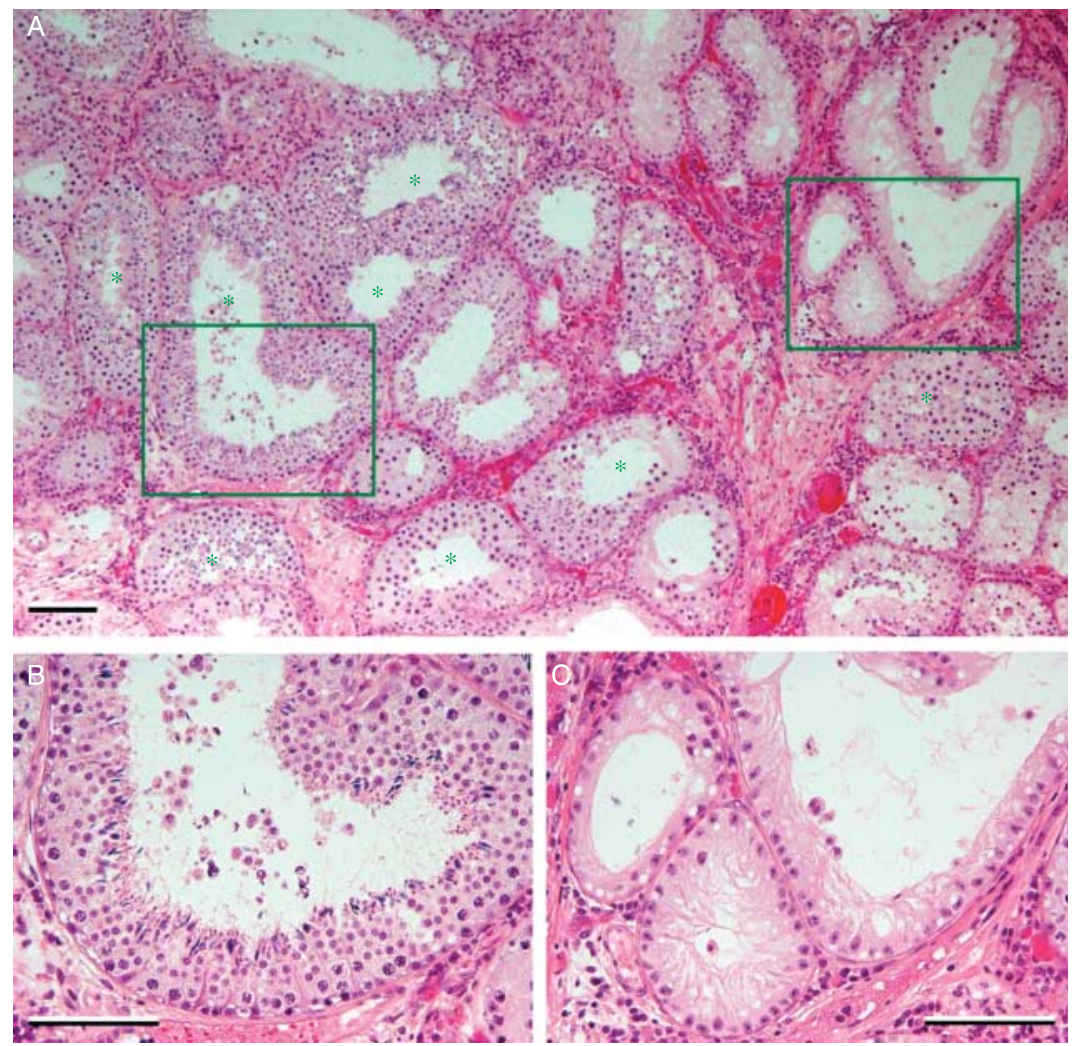

Figure 1 Plate $A$ is the histological micrograph of porcine grafted testicular tissue recovered 223 days after grafting. The tissue was fixed with Bouin's solution, embedded in paraffin, sectioned at $6 \mu \mathrm{m}$, and stained with hematoxylin and eosin. The recovered graft contained seminiferous tubules in which spermatogenesis was confirmed $(*)$. Plates B and $C$ are the magnified views of parts of Plate $A$. (B) Seminiferous tubule in which spermatogenesis has been completed. (C) Seminiferous tubules containing only Sertoli cells, with no germ cells being evident. Scale bars represent $100 \mu \mathrm{m}$.
(285/319)). Most of these xenogeneic sperm had cytoplasmic droplets $(98.2 \%(280 / 285))$, and motile sperm were obtained $(53.0 \%(151 / 285))$. Morphologically abnormal sperm, such as those with an irregularly shaped head, a malformed tail, or two heads, were also observed $(10.7 \%(34 / 319))$. In the subsequent experiments, morphologically normal sperm were used for ICSI of matured oocytes with a visible first polar body because they did not show sufficient motility for IVF (Supplementary Video 1, see section on supplementary data given at the end of this article). Some of the oocytes after ICSI possessed male and female pronuclei. We have also confirmed that these can develop in vitro to diploid blastocysts (Nakai et al. 2009; Supplementary Figure 1, see section on supplementary data given at the end of this article). To evaluate in vivo embryonic developmental ability to term, we transferred sperm-injected oocytes at $4 \mathrm{~h}$ after electrical stimulation to the oviducts of synchronized recipient gilts. In order to assist pregnancy, in some trials we co-transferred parthenogenetic oocytes without injection of spermatozoa but stimulated with an electrical pulse (King et al. 2002, Kawarasaki et al. 2009). Two out of 23 recipient gilts gave birth (Supplementary Table 1, see section on supplementary data given at the end of this article). Their pregnancy periods were 113 and 116 days after zygote transfer, and were considered to be normal (115 days). One produced a single male piglet $(0.8 \mathrm{~kg})$. This piglet subsequently grew up healthy (Fig. 2), and it was found to produce motile spermatozoa by ejaculation after 228 days. The other gilt yielded four male piglets $(1.1,1.3,1.4$, and $1.4 \mathrm{~kg})$ and one female piglet $(1.4 \mathrm{~kg})$. At 116 days of age, these piglets showed normal development. In this study, embryonic and fetal attrition, which have often been reported in cloned animals (Hill et al. 1999, Wakayama \& Perry 2002), were not checked. Furthermore, as we obtained only six piglets from two recipients in 23 transfer trials, it is still unclear whether ICSI with xenogeneic sperm is safe for production of offspring. Therefore, we will need to conduct further research on the efficacy of offspring production and normality of the offspring using sperm derived from xenografting.

To our knowledge, no previous report has confirmed the in vivo full-term developmental ability of oocytes injected with sperm from large domestic and nondomestic animal testis xenografted ectopically into immunodeficient mice. In pigs, sperm have been obtained after full spermatogenesis (Kaneko et al. 2008, Nakai et al. 2009), whereas in other large domestic animals, production of elongating spermatids has been confirmed from xenografted testicular tissue in cattle (Oatley et al. 2004, 2005, Schmidt et al. 2006) and horses (Rathi et al. 2006). There have been no such reports for nondomestic species. Considering that xenografting has been expected to become a powerful option for conserving mammalian male genetic resources, examinations should be expanded for large animal species such as cattle and 


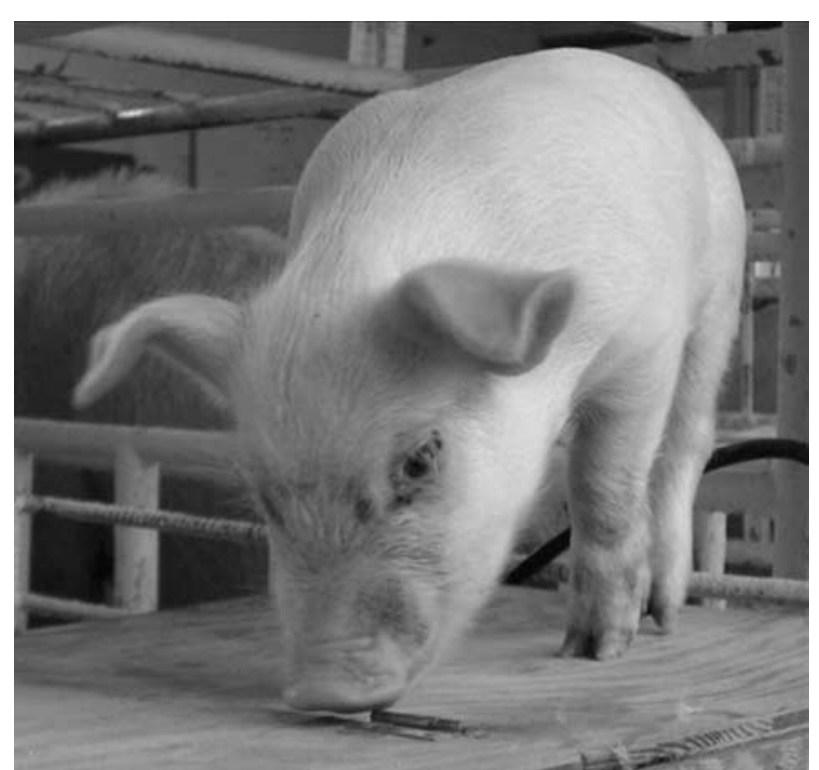

Figure 2 A male piglet produced after ICSI with xenogeneic pig sperm from neonatal testicular tissue grafted into mice. Photographed on the 50th day after birth.

horses. Furthermore, production of individuals through testicular xenografting will be useful not only for conservation of genetic resources but also for progress in biomedicine. Genetically modified pigs in particular have been a focus of interest in view of their potential as animal bioreactors for the production of biopharmaceuticals (Houdebine 2005) and as donors of xenotransplants (Niemann et al. 2003). However, there is a possibility that genetically manipulated animals might have some genetic disadvantages in reproduction, such as a degree of male infertility or carry neonatal lethal traits (Wakayama \& Perry 2002, Sun et al. 2008). In such cases, testicular xenografting might facilitate the regeneration of transgenic individuals. Furthermore, genetic manipulation of germline stem cells in grafted testicular tissue could provide a novel approach for generating transgenic offspring through the male germ cell (Oatley et al. 2004). When considering the conservation of endangered species, xenografting of testicular tissue is an indispensable technique because death of males before sexual maturation in an endangered species is directly connected with loss of biodiversity. In addition, this strategy is considered to have merits for reproductive analysis or manipulation of male fertility in large animals because physiological aspects of testicular growth or spermatogenesis in large animals may appear on an experimental basis. It has already been suggested by Honaramooz et al. (2002) that xenografting to mice provides the accessibility that is essential for studying and manipulating testis function.

The efficacy of piglet production is related to the number of viable embryos before implantation (Polge et al. 1966). It is generally accepted that pigs have a unique reproductive characteristic in that a critical pregnancy signal from several embryos is needed to establish and maintain pregnancy (Dziuk 1985). Although reports of the viability of transferred ICSI embryos in pigs are limited, the viability seems to be lower than that of conventionally fertilized oocytes. Co-transfer of parthenogenetic oocytes may be an aid to successful implantation (Kawarasaki et al. 2009). Porcine parthenogenotes can be implanted and can remain viable during the early stage of pregnancy, but they cannot develop beyond the 29th day after transfer (Kure-bayashi et al. 2000). In the present study, because we obtained piglets only in the co-transferred group (Supplementary Table 1), co-transfer of parthenogenotes may facilitate the establishment of pregnancy and term.

Our confirmation that oocytes injected with xenogeneic sperm from farm animals have full-term developmental ability will be a key step in the establishment of testicular tissue xenografting in large animals. However, further replicated examinations will be needed to assure the applicability of ectopic testicular xenografting to various fields including assisted reproduction in domestic and nondomestic animals.

\section{Materials and Methods}

\section{Testicular tissue xenografting}

Protocols for the use of animals were approved by the Animal Care Committee of the National Institute of Agrobiological Sciences, Japan. Donor testes were obtained from 6- to 12-dayold crossbred (Landrace $\times$ Large White $\times$ Duroc) piglets born at the National Institute of Livestock and Grassland Science, Tsukuba, Japan. The seminiferous cords of donor testicular tissue at the time of grafting contained only gonocytes and spermatogonia (Kaneko et al. 2008, Nakai et al. 2009). Xenografting was carried out based on the methods described in the previous reports (Kaneko et al. 2008, Nakai et al. 2009). Immediately after removal of the testis, the cortex was cut into small pieces, which were further minced into pieces measuring $\sim 1.5 \times 1.5 \times 1.5 \mathrm{~mm}$ in saline supplemented with 668 units/ $\mathrm{ml}$ penicillin (Sigma Chemical Co.) and $0.2 \mathrm{mg} / \mathrm{ml}$ streptomycin sulfate (Sigma). Five- to 8-week-old male immunodeficient mice (Crlj: CD-Foxn $1^{\text {nu}}$; Charles River Japan, Yokohama, Japan) were anesthetized and castrated. A transverse linear incision (about $0.5-1.0 \mathrm{~cm}$ in length) was then made in their back skin, and a subcutaneous space was created for grafting. Approximately, 20 pieces of donor testicular tissue were then inserted. The day of grafting was defined as day 0 in the present study.

\section{Collection of spermatozoa from grafted testicular tissue}

To obtain sperm from the testicular grafts, the grafted tissues were recovered from the mice between 133 and 280 days. The tissues were minced and dispersed in collection medium (Dulbecco's PBS; Nissui Pharmaceutical Co., Ltd, Tokyo, Japan) supplemented with $5 \mathrm{mg} / \mathrm{ml}$ BSA (Sigma). The tissue suspension was centrifuged for $10 \mathrm{~min}$ at $600 \mathrm{~g}$, and the supernatant 
was discarded. The pellet was resuspended in collection medium and maintained at room temperature until use for ICSI. Sperm morphology analysis was also carried out using tissues xenografted from a total of three mice.

\section{Oocyte collection and in vitro maturation}

Ovaries were obtained from prepubertal crossbred gilts (Landrace $\times$ Large White $\times$ Duroc breeds) at a local slaughterhouse and were transported to the laboratory at $35^{\circ} \mathrm{C}$. Cumulus-oocyte complexes (COCs) were collected from follicles that were 2-6 mm in diameter in TCM 199 (with Hanks' salts; Sigma) supplemented with $10 \%$ (v/v) fetal bovine serum (Gibco, Life Technologies), $20 \mathrm{mM}$ Hepes (Dojindo Laboratories, Kumamoto, Japan), $100 \mathrm{IU} / \mathrm{ml}$ penicillin G potassium (Sigma), and $0.1 \mathrm{mg} / \mathrm{ml}$ streptomycin sulfate (Sigma). In vitro maturation was performed as reported previously (Kikuchi et al. 2002). Briefly, about 40 COCs were cultured in $500 \mu \mathrm{l}$ of maturation medium for 20-22 h in fourwell dishes (Nunclon Multidishes; Nalge Nunc International, Rochester, NY, USA). The medium that was used was modified North Carolina State University (NCSU)-37 solution containing $10 \%(\mathrm{v} / \mathrm{v})$ porcine follicular fluid, $0.6 \mathrm{mM}$ cysteine, $50 \mu \mathrm{M}$ $\beta$-mercaptoethanol, $1 \mathrm{mM}$ dibutyl cAMP (dbcAMP; Sigma), $10 \mathrm{IU} / \mathrm{ml}$ eCG (PMS 1000 Tani NZ; Nihon Zenyaku Kogyo, Koriyama, Japan), and $10 \mathrm{IU} / \mathrm{ml}$ hCG (Puberogen $1500 \mathrm{U}$; Sankyo, Tokyo, Japan). The COCs were subsequently cultured for $24 \mathrm{~h}$ in maturation medium without dbcAMP and hormones. Maturation culture was carried out at $39^{\circ} \mathrm{C}$ under conditions in which $\mathrm{CO}_{2}, \mathrm{O}_{2}$, and $\mathrm{N}_{2}$ were adjusted to 5, 5, and $90 \%$ respectively $\left(5 \% \mathrm{O}_{2}\right)$. After culture, cumulus cells were removed from the oocytes by treatment with $150 \mathrm{IU} / \mathrm{ml}$ hyaluronidase (Sigma) and gentle pipetting. Denuded oocytes with the first polar body were harvested under a stereomicroscope, and they served as in vitro matured oocytes.

\section{ICSI and oocyte stimulation}

ICSI was carried out as described previously (Nakai et al. 2003, 2006, 2007, 2009). Two solutions were prepared for ICSI: 1) for oocytes, modified NCSU-37 without glucose but supplemented with $0.17 \mathrm{mM}$ sodium pyruvate, $2.73 \mathrm{mM}$ sodium lactate, $4 \mathrm{mg} / \mathrm{ml} \mathrm{BSA}$, and $50 \mu \mathrm{M} \beta$-mercaptoethanol (IVC-PyrLac; Kikuchi et al. 2002), and supplemented with $20 \mathrm{mM}$ Hepes, with the osmolality being adjusted to $285 \mathrm{mOsm} / \mathrm{kg}$ (IVC-PyrLac-Hepes; Nakai et al. 2003, 2006, 2007, 2009), and 2) for sperm, IVC-PyrLac-Hepes supplemented with 4\% (w/v) polyvinylpyrrolidone (MW 360 000; Sigma; IVCPyrLac-Hepes-PVP). Sperm were injected as described previously (Nakai et al. 2009). About 20 in vitro oocytes were transferred to a $20-\mu$ l drop of IVC-PyrLac-Hepes. The solution containing the mature oocytes was placed on the cover of a plastic dish (Falcon 35-1005; Becton Dickinson and Company, Franklin Lakes, NJ, USA). A small volume $(0.5 \mu \mathrm{l})$ of the sperm suspension was transferred to a $2-\mu$ l drop of IVC-PyrLac-Hepes-PVP, which was prepared close to the drops used for the oocytes. All drops were covered with paraffin oil (Paraffin Liquid; Nakarai Tesque, Inc., Kyoto, Japan). A single sperm was aspirated tail first from the suspension into the injection pipette, and the pipette was moved to the drop containing the oocyte. The sperm was injected into the ooplasm using a Piezo-actuated micromanipulator (PMAS-CT150; Prime Tech Ltd, Tsuchiura, Japan). One hour after the injection, the sperm-injected oocytes (20 in all) were transferred to an activation solution consisting of $0.28 \mathrm{M}$ D-mannitol, $0.05 \mathrm{mM}$ $\mathrm{CaCl}_{2}, 0.1 \mathrm{mM} \mathrm{MgSO}_{4}$, and $0.1 \mathrm{mg} / \mathrm{ml} \mathrm{BSA}$ and were washed once. They were then stimulated with a direct current pulse of $1.5 \mathrm{kV} / \mathrm{cm}$ for $20 \mu \mathrm{s}$ using a somatic hybridizer (SSH-10; Shimadzu, Kyoto, Japan). Parthenogenetic oocytes for assisted pregnancy were generated by electrostimulation with a direct pulse of $2.2 \mathrm{kV} / \mathrm{cm}$ for $30 \mu$ s and were incubated in $10 \mu \mathrm{g} / \mathrm{ml}$ cytochalasin B for $3 \mathrm{~h}$.

\section{Transfer of xenogeneic sperm-injected oocytes}

Recipient gilts were housed in isolation from boars. Estrus synchronization of the recipient gilts was induced by an i.m. injection of 1000 IU of eCG (Nihon Zenyaku Kogyo), followed $72 \mathrm{~h}$ later by an injection of 500 IU of hCG (Sankyo). Ovulation was expected at 40-45 h after the hCG injection. The oocytes were surgically transferred to both oviducts of recipient gilts. Pregnancy was diagnosed in the recipients by using an echographic pregnancy detector (Fujihira, Tokyo, Japan) for detection of the placental cavity.

\section{Supplementary data}

This is linked to the online version of the paper at http://dx.doi. org/10.1530/REP-09-0509.

\section{Declaration of interest}

The authors declare that there is no conflict of interest that would prejudice the impartiality of this scientific work.

\section{Funding}

This study was supported in part by Grants-in-Aid for Scientific Research (21380175 to H Kaneko and 71310042 to M Nakai) from the Japanese Society for Promotion of Science (JSPS) and also in part by the Promotion and Mutual Aid Corporation for Private Schools of Japan, and by a Grant-in-Aid for Matching Fund Subsidy for Private Universities to J Ito and N Kashiwazaki.

\section{Acknowledgements}

The authors would like to thank Dr M Fahrudin and Dr N W K Karja for critical discussion of the present study, and also Ms T Aoki, Ms M Oosaki, and Ms K Kaneko for technical assistance.

\section{References}

Dziuk P 1985 Effect of migration, distribution and spacing of pig embryos on pregnancy and fetal survival. Journal of Reproduction and Fertility Supplement 33 57-63. 
Hill JR, Roussel AJ, Cibelli JB, Edwards JF \& Hooper NL 1999 Clinical and pathologic features of cloned transgenic calves and fetuses (13 case study). Theriogenology 51 1451-1465.

Honaramooz A, Snedaker A, Boiani M, Scholer H, Dobrinski I \& Schlatt S 2002 Sperm from neonatal mammalian testes grafted in mice. Nature 418 778-781.

Honaramooz A, Li MW, Penedo MCT, Meyers S \& Dobrinski I 2004 Accelerated maturation of primate testis by xenografting into mice. Biology of Reproduction 70 1500-1503.

Honaramooz A, Cui XS, Kim NH \& Dobrinski I 2008 Porcine embryos produced after intracytoplasmic sperm injection using xenogeneic pig sperm from neonatal teitis tissue grafted in mice. Reproduction, Fertility and Development 20 802-807.

Houdebine LM 2005 Use of transgenic animals to improve human health and animal production. Reproduction in Domestic Animals 40 269-281.

Kaneko H, Kikuchi K, Nakai M \& Noguchi J 2008 Endocrine status and development of porcine testicular tissues in host mice. Journal of Reproduction and Development $\mathbf{5 4}$ 480-485.

Kawarasaki T, Otake M, Tsuchiya S, Shibata M, Matsumoto K \& Isobe N 2009 Co-transfer of parthenogenotes and single porcine embryos leads to full-term development of the embryos. Animal Reproduction Science $1128-21$.

Kikuchi K, Onishi A, Kashiwazaki N, Iwamoto M, Noguchi J, Kaneko H, Akita T \& Nagai T 2002 Successful piglet production after transfer of blastocysts produced by a modified in vitro system. Biology of Reproduction 66 1033-1041.

King TJ, Dobrinsky JR, Zhu J, Finlayson HA, Bosma W, Harkness L, Ritchie WA, Travers A, McCorqquodale C, Day BN et al. 2002 Embryo development and establishment of pregnancy after embryo transfer in pigs: coping with limitations in the availability of viable embryos. Reproduction 123 507-515.

Kure-bayashi S, Miyake M, Okabe K \& Kato S 2000 Successful implantation of in vitro matured, electro activated oocytes in the pig. Theriogenology 53 1105-1119.

Nakai M, Kashiwazaki N, Takizawa A, Hayashi Y, Nakatsukasa E, Fuchimoto D, Noguchi J, Kaneko H, Shino M \& Kikuchi K 2003 Viable piglets generated from porcine oocytes matured in vitro and fertilized by intracytoplasmic sperm head injection. Biology of Reproduction $\mathbf{6 8}$ 1003-1008.

Nakai M, Kashiwazaki N, Takizawa A, Maedomari N, Ozawa M, Noguchi J, Kaneko H, Shino M \& Kikuchi K 2006 Morphological changes in boar sperm nuclei with reduced disulfide bonds in electrostimulated porcine oocytes. Reproduction 131 603-611.

Nakai M, Kashiwazaki N, Takizawa A, Maedomari N, Ozawa M, Noguchi J, Kaneko H, Shino M \& Kikuchi K 2007 Effects of chelating agents during freeze-drying of boar spermatozoa on DNA fragmentation and on developmental ability in vitro and in vivo after intracytoplasmic sperm head injection. Zygote 15 15-24.

Nakai M, Kaneko H, Somfai T, Maedomari N, Ozawa M, Noguchi J, Kashiwazaki N \& Kikuchi K 2009 Generation of porcine diploid blastocysts after injection of spermatozoa grown in nude mice. Theriogenology 72 2-9.
Niemann H, Rath D \& Wrenzycki C 2003 Advances in biotechnology: new tool in future pig production for agriculture and biomedicine. Reproduction in Domestic Animals 38 82-89.

Oatley JM, de Avila DM, Reeves JJ \& McLean DJ 2004 Spermatogenensis and germ cell transgene expression in xenografted bovine testicular tissue. Biology of Reproduction 71 494-501.

Oatley JM, Reeves JJ \& McLean DJ 2005 Establishment of spermatogenesis in neonatal bovine testicular tissue following ectopic xenografting varies with donor age. Biology of Reproduction 72 358-364.

Polge C, Rowson LE \& Chang MC 1966 The effect of reducing the number of embryos during early stages of gestation on the maintenance of pregnancy in the pig. Journal of Reproduction and Fertility 12 395-397.

Rathi R, Honaramooz A, Zeng W, Turner R \& Dobrinski I 2006 Germ cell development in equine testis tissue xenografted into mice. Reproduction 131 1091-1098.

Schlatt S, Samuel Kim S \& Gosden R 2002 Spermatogenesis and steroidogenesis in mouse, hamster and monkey testicular tissue after cryopreservation and heterotopic grafting to castrated hosts. Reproduction 124 339-346.

Schlatt S, Honaramooz A, Boiani M, Scholer HR \& Dobrinski I 2003 Progeny from sperm obtained after ectopic grafting of neonatal mouse testes. Biology of Reproduction 68 2331-2335.

Schmidt JA, De Avila JM \& McLean DJ 2006 Grafting period and donor age affect the potential for spermatogenesis in bovine ectopic testis xenografts. Biology of Reproduction 75 160-166.

Shinohara T, Inoue K, Ogonuki N, Kanatsu-Shinohara M, Miki H, Nakata K, Kurome M, Nagashima H, Toyokuni S, Kogishi K et al. 2002 Birth of offspring following transplantation of cryopreserved immature testicular pieces and in vitro microinsemination. Human Reproduction 17 3039-3045.

Snedaker AK, Honaramooz A \& Dobrinski I 2004 A game of cat and mouse: xenografting of testis tissue from domestic kittens results in complete cat spermatogenesis in a mouse host. Journal of Andrology 25 926-930.

Sun QY, Liu K \& Kikuchi K 2008 Oocyte-specific knockout: a novel in vivo approach for studying gene functions during folliculogenesis, oocyte maturation, fertilization, and embryogenesis. Biology of Reproduction 79 1014-1020.

Wakayama T \& Perry AC 2002 Cloning of mice. In Principles of Cloning, pp 301-341. Eds JB Cibell, RP Lanza, KH Campbell \& MD West. San Diego: Academic Press.

Zeng W, Avelar GF, Rathi R, Franca LR \& Dobrinski I 2006 The length of the spermatozoaatogenic cycle is conserved in porcine and ovine testis xenografts. Journal of Andrology 27 527-533.

Zeng W, Rathi R, Pan H \& Dobrinski I 2007 Comparison of grobal gene expression between porcine testis tissue xenografts and porcine testis in situ. Molecular Reproduction and Development 74 674-679.

Received 11 May 2009

First decision 12 June 2009

Revised manuscript received 2 December 2009

Accepted 9 December 2009 